\title{
Oxidative stress accelerates the carotid atherosclerosis process in patients with chronic kidney disease
}

Leila Toualbi Azouaou ${ }^{1}$, Mounir Adnane ${ }^{2}$, Abderrezak Khelfi ${ }^{3}$, Wafa Ballouti ${ }^{4}$, Medina Arab $^{5}$, Chahine Toualbi ${ }^{6}$, Henni Chader ${ }^{7}$, Rayane Tahae ${ }^{8}$, Atmane Seba ${ }^{9}$

\author{
${ }^{1}$ Department of Nephrology, Parnet Hospital Universite, Algiers, Algieria \\ ${ }^{2}$ Department of Biomedicine, Institute of Veterinary Sciences, University of Tiaret, \\ Tiaret, Algeria \\ ${ }^{3}$ Departement of Toxicology, Hospital University of Bab el oued, Algiers, Algeria \\ ${ }^{4}$ Department of Biochemistry, Hospital of Hussein Dey, Algiers, Algeria \\ ${ }^{5}$ Department of Biochemestry, Hospital University of Mustapha Bacha, Algiers, Algeria \\ ${ }^{6}$ Department of Orthopedic Surgery, Hospital of Bejaia, Bejaia Algeria \\ ${ }^{7}$ Department of Pharmacology, Pastor Institute, Algiers, Algeria \\ ${ }^{8}$ Department of Nephrology, Hospital University of Hussein Dey, Algiers, Algeria \\ ${ }^{9}$ Department of Nephrology, Hospital University of Tizi ouzou, Tizi Ouzou, Algeria
}

Submitted: 24 April 2020

Accepted: 15 August 2020

Arch Med Sci Atheroscler Dis 2020; 5: e245-e254

DOI: https://doi.org/10.5114/amsad.2020.98945

Copyright $\odot 2020$ Termedia \& Banach

\begin{abstract}
Introduction: The atherosclerosis process is highly accelerated in patients with chronic kidney disease (CKD). Oxidative stress is considered as one of the pro-atherogenic factors involved in accelerating the atherosclerosis process of the carotid artery. The aim of the present study was to determine the relationship between oxidative stress markers and the progression of carotid atherosclerosis in CKD patients.

Material and methods: The study was conducted on 162 patients with CKD and 40 controls, and the disease stage was scored between 2 and 5D. Blood samples were taken and advanced oxidative protein product, myeloperoxidases, malondialdehyde, nitric oxide, glutathione, and oxidised low-density lipoprotein were measured. Furthermore, we studied the correlations between these biomarkers and clinical and para-clinical cardiovascular complications. Results: The average age of patients was 56.5 years. The oxidative stress markers average \pm SD levels in CKD groups compared to the control were as follows: advanced oxidation protein product ( $61.89 \pm 1.4$ vs. $26.65 \pm 1.05$ $\mu \mathrm{mol} / \mathrm{l})$, myeloperoxidase $(59.89 \pm 1.98 \mathrm{vs}$. $38.45 \pm 1.98 \mathrm{UI} / \mathrm{ml})$, malondialdehyde $(6.1 \pm 0.12$ vs. $3.26 \pm 0.03 \mu \mathrm{mol} / \mathrm{l})$, nitric oxide $(65.82 \pm 1.06$ vs. 52.19 $\pm 2.1 \mu \mathrm{mol} / \mathrm{l})$, glutathione $(52.21 \pm 1.3 \mathrm{vs} .89 .4 \pm 2.6 \mathrm{IU} / \mathrm{ml})$, and oxLDL $(15.57$ \pm 1.07 vs. $1.72 \pm 0.82 \mu \mathrm{mol} / \mathrm{l})$. While the glutathione level decreased significantly in advanced CKD stage $(p<0.05)$, the concentrations of all the other biomarkers increased significantly in accordance with CKD score $(p<0.05)$. Conclusions: Cardiovascular diseases, mainly atherosclerosis, can be diagnosed indirectly by measuring oxidative stress markers. Furthermore, theses markers can be used to predict the progression of CKD, for better management of the disease.
\end{abstract}

Key words: oxidative stress, oxidised low-density lipoprotein, cardiovascular disease, chronic kidney disease.

\section{Introduction}

Chronic kidney disease (CKD) is considered as a major public health burden [1]. The number of patients reaching the end-stage renal disease

\author{
Corresponding author: \\ Prof. Leila Toualbi Azouaou \\ Hospital CHU Parnet \\ Universite \\ Algiers, Algeria \\ E-mail: \\ azouaouliela@yahoo.fr
}


(ESRD) and requiring haemodialysis is constantly increasing, mainly in elderly people in developed countries [2]. Indeed, aging represents a major risk factor for CKD and ESRD by increasing the occurrence of diabetic and vascular nephropathies [3-5].

CKD is often associated with cardiovascular complications [6]. Age, sex, high blood pressure, diabetes, smoking, obesity, and dyslipidaemia are considered as common risk factors for classic cardiovascular diseases and CKD and may explain the high mortality level reported in CKD patients [7-11]. Several risk factors for non-traditional cardiovascular diseases were reported in CKD, among which oxidative stress [12], malnutrition, inflammation, hyperhomocysteinaemia, phosphocalcic metabolism abnormalities, and anaemia were more often implicated [13].

Oxidative stress is simply defined as all the molecular alterations within the organism cells induced by an increased production of reactive oxygen species (ROS), which escape to mechanisms of antioxidant stress regulation [12].

We believe that detecting oxidative stress in CKD patients at an early stage would help to effectively manage the disease and prevent severe complications [14]. Oxidative stress is diagnosed by measuring several markers in blood, mainly malondialdehyde (MDA) for lipid peroxidation [15], advanced oxidation protein product (AOPP) for protein oxidation [16], oxidized low-density lipoprotein (oxLDL) for lipoproteins oxidation, and various markers for nucleic acid oxidation mainly 8-hydroyguanine [17]. Also, it is of major interest to monitor the effectiveness of antioxidant mechanism by measuring enzymatic, such superoxide dismutase (SOD) and glutathione peroxidase (GPX) [18] and non-enzymatic antioxidant markers such as vitamins $C$ and $E$ and coenzyme Q10 (CoQ10) [19].

For ideal functioning of different organs, cells structure and functions must be well kept and controlled for toxin accumulation and membrane integrity. Likewise, vascular endothelium plays a key role in the vascular tone regulation in response to different stimuli such as prostacyclin, endothelin, and nitric oxide (NO) [20]. The various cell types constituting the vascular wall produce in abundance radical and non-radical ROS and reactive nitrogen species (RNS) [21], responsible for oxidative stress development. ROS and RNS are important modulators of signal transduction pathways and gene expression, which are implicated in the normal vascular homeostasis [22]. Any disruption of this balance will induce endothelial problems [23]. Oxidative stress and inflammation are two major proatherogenic factors, responsible for modification of vascular wall integrity [24].
The vascular wall integrity and cellular function can be compromised by several factors such as hypertension, hypercholesterolaemia, and diabetes, which induce harmful oxidative stress through the activation of nicotinamide adenine dinucleotide phosphate $\mathrm{NAD}(\mathrm{P}) \mathrm{H}$ oxidases and the mitochondrial respiratory chain, and by decreasing NO bioavailability [25].

Atherosclerotic lesions begin following a pro-oxidant imbalance, leading to oxLDL formation and multiple cellular dysfunctions such as synthesis of pro-inflammatory mediators and promotion of cell proliferation factors, in addition to the adhesion of monocytes to the endothelial cells, platelet aggregation, cellular apoptosis or necrosis, and finally the rupture of atherosclerotic plaques [26].

In the atheroma plaque, several macrophage populations were identified with different phenotypes linked to inflammation (pro-inflammatory: M1, anti-inflammatory: M2) or with redox changes in the environment (Mox), increased oxidative stress markers such as AOPP, myeloperoxidases (MPO), and decreased antioxidant markers such as gluthations [27]. It seems that oxidative stress and inflammation are crosslinked and play an important role in (i) endothelial dysfunction, by decreasing endothelial NO (eNO) bioavailability and increasing inducible NO (iNO), (ii) LDL oxidation, (iii) lesion remodelling by proteases and antiproteases regulation, and (iv) smooth muscle cell (CML) proliferation, because $C M L$ are the second most abundant cell type in atherosclerotic damage after macrophages. CML hyperproliferation results from cells dedifferentiation from a contractile secretory phenotype, increasing their proliferative and migratory capacity [28].

Intracellular lipids oxidation such as malondialdehyde (MDA) is a common pathophysiological response to oxidative stress and hyperlipidaemia. oxLDL contains hundreds of different oxidised lipid molecules [29]. oxLDL can be found in various abnormal cells such as apoptotic cells and in pathological tissues and in the blood stream in the case of different diseases [30]. Therefore, we believe that oxLDL is a valuable biomarker for hyperlipidaemia and atherosclerosis. oxLDL molecules penetrate the subendothelial space where they undergo many oxidative modifications induced by ROS produced by the wide cell population of blood vessels, mainly monocytes, endothelial cells, and vascular smooth muscle cells (VSMCs) [31], leading to the development of atherosclerosis.

The aim of the study is to determine the relationship between candidate oxidative stress markers and the acceleration of the carotid atherosclerosis process in patients with CKD. 


\section{Material and methods}

A descriptive longitudinal study with prospective collection was conducted on 162 patients with CKD within the nephrology service of Parnet hospital during the period of 2015-2017. All CKD patients had blood samples taken to measure oxidative stress markers. Furthermore, paraclinical explorations were conducted for all CKD patients using supra-aortic trunk echo-Doppler (TSA) and echocardiography to diagnose possible cardiovascular complications. Patients were medically controlled every three months for 2 years to control the cardiovascular activity and possible complications. As a control group, 40 people were recruited for the study.

\section{Study population}

We included in the study all CKD patients, over the age of 18 years, of various aetiologies, and at different stages of development, including haemodialysis patients. As inclusion criteria, CKD patients were in a stable clinical situation and were not receiving injectable iron during the 3 months before the onset of the study. Injectable iron was an exclusion criterion because it generates high levels of oxygenated free radicals [32]. All CKD patients with pre-existing heart disease before the diagnosis of CKD, severe valvular disease, constrictive pericarditis, systolic dysfunction with ejection fraction (ER) $<50 \%$, haemodialysis for less than 6 months, glomerular filtration rate (GFR) $>90 \mathrm{ml} / \mathrm{min}$, and peritoneal dialysis were excluded from the study.

The CKD patients included in the study were categorised into five groups according to Kidney Disease: Improving Global Outcomes (KDIGO) 2012 [33] with modification. CKD stage was estimated by calculating the level of creatinine clearance, using the formula proposed in the Modification of the Diet in Renal Disease (MDRD) study [34]. Briefly, stage 2 included patients $(n=31)$ with mild CKD symptoms and creatinine clearance of $60-89 \mathrm{ml} / \mathrm{min}$. Stage 3 included patients with moderate CKD symptoms $(n=41)$ with creatinine clearance of 30-59 $\mathrm{ml} / \mathrm{min}$. Stage 4 included patients $(n=31)$ with severe CKD symptoms associated to creatinine clearance of $15-29 \mathrm{ml} / \mathrm{min}$. Stage 5 regrouped CKD patients $(n=25)$ with very severe symptoms and creatinine clearance lower than $15 \mathrm{ml} / \mathrm{min}$, while patients with very severe CKD symptoms and receiving haemodialysis were categorised at stage 5D $(n=32)$.

\section{Blood sampling and measurement of oxidative stress markers}

Blood samples were taken from the CKD patients included in the study using tubes containing ethylenediaminetetraacetic dipotassium acid
(EDTA K2). Samples were centrifuged for $10 \mathrm{~min}$ at $4500 \mathrm{rpm}$ (3900 g). Plasma was collected and aliquoted in $1.5 \mathrm{ml}$ Eppendorf tubes and stored at $-20^{\circ} \mathrm{C}$ until further analysis.

AOPP [35], MPO, glutathione, and NO were measured in plasma by the colorimetric method suing a spectrophotometer [36-39]. In the present study we only measured the NO secreted by inducible NO-synthase (iNOS) for their known pro-oxidative role. NO was measured by the quantification of two physiological metabolites of NO: nitrites $\left(\mathrm{NO}_{2}^{-}\right)$and nitrates $\left(\mathrm{NO}_{3}^{-}\right)$according to Griess (1879).

oxLDL [40] was measured by enzyme-linked immunosorbent assay (ELISA) using Human Oxidised low-density lipoprotein (OxLDL) ELISA Kit (abx253899, Abbexa Ltd, 181 Cambridge Science Park, Cambridge CB4 OGJ, United Kingdom), following the manufacturer instructions.

MDA was measured in plasma using high-performance liquid chromatography (HPLC) using Chromolith ${ }^{\circledR}$ RP-18 Endcapped HPLC Columns (Merck Worldwide Headquarters, 400 Summit Drive Burlington, Massachusetts, 1803USA) according to the protocol proposed by Nielsen et al. (1997) and Michel et al. [41].

\section{Echocardiography}

Clinical examination for heart function was conducted using echocardiograph (GE VIVID S6 Ultrasound Machine, KPI Healthcare Inc., 23865 Vía del Rio, Yorba Linda, CA 92887, United States) equipped with a $3.5 \mathrm{MHz}$ probe and functional on Time Movement (TM), two-dimension (2D), and Doppler modes (pulsed, continuous, colour, and tissue). Echocardiography was used to measure the left ventricular diameter and the thickness of its walls [42]. Furthermore, left ventricular mass (LVM) was measured using linear M mode according to the following formula (ASE: American Society of Echocardiography guidelines): $L V M=0.8$ $\times\{1.04[($ LVIDd + PWTd + SWTd $) 3-($ LVIDd) 3] $\}+$ $0.6 \mathrm{~g}$, where, LVIDd - left ventricular internal diameter in diastole, PWTd - posterior wall telediastolic, SWTd - posterior septal wall telediastolic.

Left ventricular geometry was analysed according to the ratio DTIS/DTPW (diastolic thickness of the interventricular septum [DTIS]/diastolic thickness of the posterior wall [DTPW]), according to [43-45].

Supra-aortic trunk echo-Doppler (TSA) technique was conducted using a Toshiba Xario ultrasound equipped with a $3.5 \mathrm{MHz}$ probe to analyse the carotid and vertebral axes. The carotid axis examination focused on the primary carotid, carotid bifurcation, and internal and external carotids. The vertebral artery was scanned starting from its origin and in its intervertebral part. The brachioce- 
phalic arterial trunk and the two subclavian arteries were also monitored. The intima-media thickness (IMD) of the primitive carotid was measured on the posterior wall of the primitive carotid at a distance from a plate and the carotid bifurcation [46]. The measurement of IMT includes both the internal and medium borders of the arterial wall, and a thickness $\geq 1 \mathrm{~mm}$ was considered as pathological. The upper limit of the IMT for healthy patients was fixed at a threshold of $0.75 \mathrm{~mm}$.

\section{Statistical analysis}

Statistical analysis was conducted using Statistical Package of Social Sciences software (IBM SPSS Statistics V22, IBM, 1 New Orchard Road, Armonk, New York 10504-1722, United States). Student's $t$ test was used for means comparison of two variables, ANOVA test was used to compare more than two variables in parametric tests, while for the non-parametric tests we used Welch and Brown-Forsythe tests. The Tukey and Hartmane test was used for multiple comparisons. A chi-square $\left(\chi^{2}\right)$ was used for comparison of qualitative variables. The Pearson test was used for the linear correlations. For multivariate studies of independent factors, we used a logistic regression model with Wald type step by step test in which all factors with a $p<0.1$ were included in analysis. Tests were considered statistically significant at $p<0.05$.

\section{Results}

We measured the markers of oxidative stress in different population groups, and values were compared using the Tukey test for multiple comparisons. The average \pm standard deviation (SD) levels of inflammatory marker high-sensitivity C-reactive protein (hs-CRP) in CKD groups compared to the control group was $3.64 \pm 0.21$ against $0.57 \pm 0.05 \mathrm{mg} / \mathrm{l}$, respectively (Table I). For the oxidative stress markers, the average \pm SD levels in CKD groups compared to the control were as follows; AOPP (61.89 $\pm 1.4 \mathrm{vs}$. $26.65 \pm 1.05 \mu \mathrm{mol} / \mathrm{l})$, MPO (59.89 \pm 1.98 vs. 38.45 $\pm 1.98 \mathrm{Ul} / \mathrm{ml}), \mathrm{MDA}(6.1 \pm 0.12$ vs. $3.26 \pm 0.03 \mu \mathrm{mol} / \mathrm{l})$, NO $(65.82 \pm 1.06$ vs. $52.19 \pm 2.1 \mu \mathrm{mol} / \mathrm{l})$, glutathione (52.21 \pm 1.3 vs. $89.4 \pm 2.6 \mathrm{IU} / \mathrm{ml})$, and oxLDL (15.57 \pm 1.07 vs. $1.72 \pm 0.82 \mu \mathrm{mol} / \mathrm{l}$ ) (Table I).

The levels of NO, AOPP, oxLDL, MDA, and MPO increased significantly with creatinine, and thus with the degradation of kidney function (Figure 1). The lowest values of the above markers were reported in the control group (stage 1), while the highest values were registered in CKD patients with very severe symptoms of kidney failure (stage 5 ) and with haemodialysis (stage 5D) $(p<0.05)$. Unlike all the other markers, glutathione levels decreased signifi-

Table I. General characteristics, inflammatory markers, and oxidative stress markers of each group. Oxidative stress markers were compared between each CKD group and the control

\begin{tabular}{|c|c|c|c|c|c|c|}
\hline Parameter & Control & Stage 2 & Stage 3 & Stage 4 & Stage 5 & Stage $5 d$ \\
\hline$N$ & 40 & 31 & 41 & 31 & 25 & 32 \\
\hline Age & $45 \pm 11.8$ & $58.5 \pm 13.4$ & $62.0 \pm 16$ & $66.1 \pm 13.9$ & $50.2 \pm 12.8$ & $43.3 \pm 12.8$ \\
\hline BMI & $25.7 \pm 3.45$ & $25.1 \pm 2.5$ & $24.1 \pm 3.31$ & $22.2 \pm 2.06$ & $20.1 \pm 1.74$ & $17.6 \pm 1.12$ \\
\hline hsCRP & $0.57 \pm 0.05$ & $0.79 \pm 0.08$ & $2.34 \pm 0.14$ & $3.29 \pm 0.16$ & $4.66 \pm 0.22$ & $7.53 \pm 0.47$ \\
\hline Prevalence LVH & $2.8 \%$ & $35.5 \%$ & $51.2 \%$ & $64.5 \%$ & $70.4 \%$ & $87.5 \%$ \\
\hline \multicolumn{7}{|c|}{ Medium intima media diameter of the carotid artery: } \\
\hline$<0.75$ & $97.8 \%$ & $93.5 \%$ & $90.2 \%$ & $74.2 \%$ & $55.6 \%$ & $6.3 \%$ \\
\hline $0.75-1$ & $2.2 \%$ & $6.5 \%$ & $9.8 \%$ & $25.8 \%$ & $29.6 \%$ & $65.6 \%$ \\
\hline$>1$ & $0 \%$ & $0 \%$ & $0 \%$ & $0 \%$ & $14.8 \%$ & $28.1 \%$ \\
\hline $\mathrm{NO}[\mu \mathrm{mo} / \mathrm{l}]$ & $52.19 \pm 2.1$ & $61.75 \pm 2.34^{\circ}$ & $63.91 \pm 2.21 \cdots$ & $64.08 \pm 2.18 \cdots$ & $67 \pm 2.7^{1 \cdots .}$ & $72.45 \pm 2.17^{1 \cdots}$ \\
\hline $\mathrm{AOPP}[\mu \mathrm{mo} / \mathrm{l}]$ & $26.65 \pm 1.05$ & $40.75 \pm 0.82 \cdots$ & $53.54 \pm 2.01 \cdots$ & $63.9 \pm 2.8 \cdots$ & $72.37 \pm 2.09 \cdots$ & $82.75 \pm 2.19 \cdots$ \\
\hline $\mathrm{oxLDL}[\mu \mathrm{mo} / \mathrm{l}]$ & $1.72 \pm 0.82$ & $3.2 \pm 0.47$ & $6.51 \pm 1 \cdots$ & $13.32 \pm 1.42 \cdots$ & $21.67 \pm 1.92^{1 \cdots .}$ & $35.78 \pm 0.98^{1 \cdots}$ \\
\hline $\mathrm{MDA}[\mu \mathrm{mo} / \mathrm{l}]$ & $3.26 \pm 0.03$ & $3.99 \pm 0.08^{\circ}$ & $5.23 \pm 0.05 \cdot$ & $6.13 \pm 0.07^{1 \cdots .}$ & $7.23 \pm 0.07^{1 \cdots}$ & $8.27 \pm 0.11^{1 \cdots .}$ \\
\hline MPO [UI /ml] & $38.45 \pm 1.98$ & $43.95 \pm 2.4^{\circ}$ & $50.01 \pm 2.54 \cdot \cdot$ & $46.38 \pm 2.83 \cdots$ & $72.21 \pm 4.01 \cdots$ & $88.65 \pm 4.09 \cdots$ \\
\hline $\begin{array}{l}\text { Glutathione } \\
{[\mathrm{Ul} / \mathrm{ml}]}\end{array}$ & $89.4 \pm 2.6$ & $89.4 \pm 2.6 \cdots$ & $71.7 \pm 1.6 \cdots$ & $62.7 \pm 1^{1 \cdots \cdots}$ & $52.2 \pm 1.8^{1 \cdots}$ & $40.4 \pm^{1 \cdots .}$ \\
\hline
\end{tabular}

$B M I$ - body mass index, $L V H$ - left ventricular hypertrophy, hs-CRP - high-sensitivity C-reactive protein, NO - nitric oxide, AOPP - advanced oxidative protein products, oxLDL - oxidised low-density lipoprotein, MDA - malondialdehydes, MPO - myeloperoxidases. $\cdot P<0.05$, $\cdots p<0.01, \cdots p<0.001, \cdots p<0.0001$ 

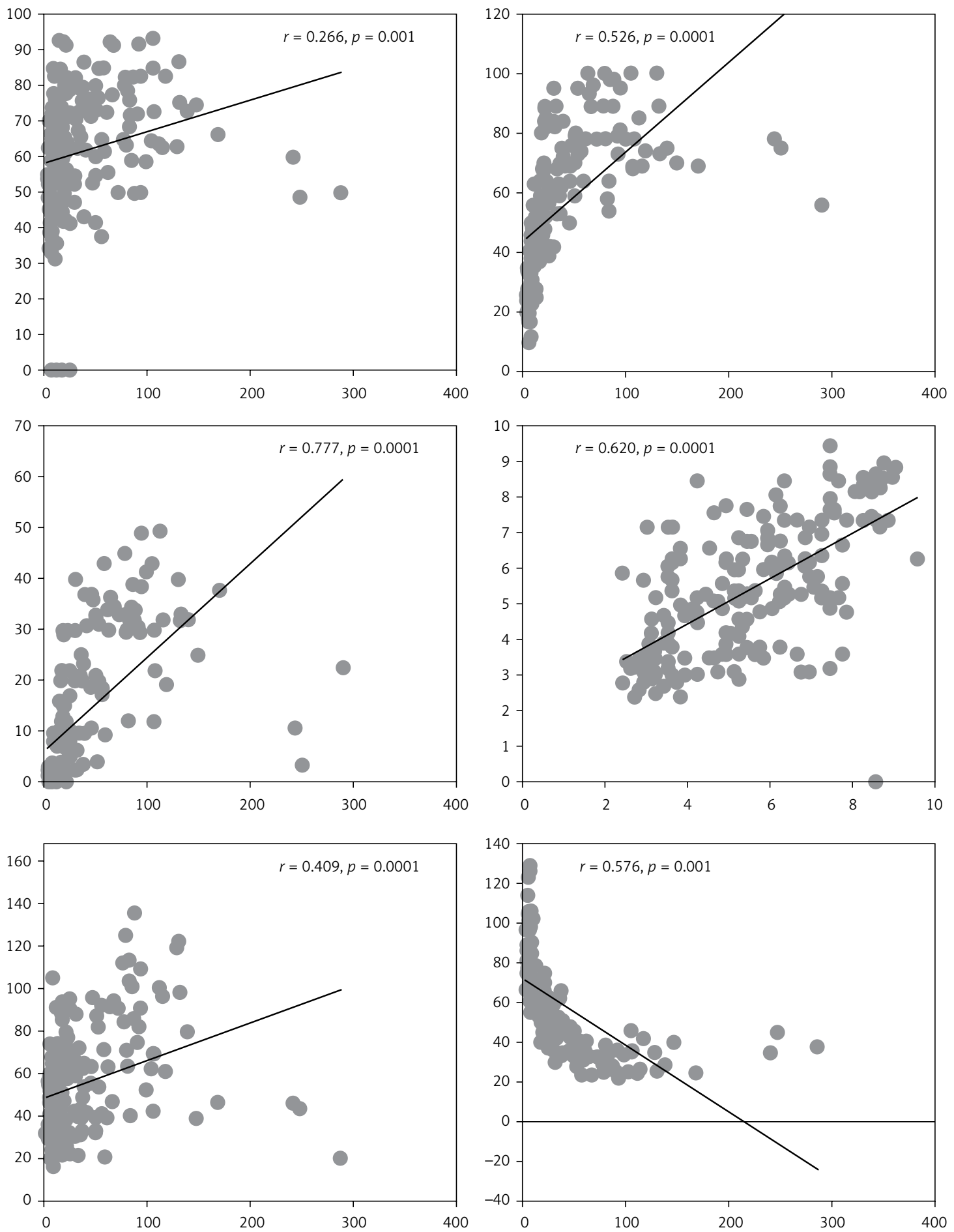

Figure 1. Correlation of oxidative stress markers and creatinine levels in the studied population. NO, AOPP, oxLDL, MDA and MPO were positively correlated with creatinine level in CKD patients. However, glutathione was negatively associated with creatinine level and decreased with the progression of kidney failure stage

cantly while creatinine levels increase and the CKD symptoms were more severe $(p<0.05)$ (Figure 1 ).

The intima media diameter of the carotid artery (IMD) was monitored by TSA, and values were compared to the levels of oxidative stress markers (Table II).

Patients with high IMD (>1 mm) had higher values of the prooxidant markers (NO, AOPP, ox-
LDL, MDA, MPO) but lower antioxidant marker values (glutathione), compared to other patients with lower IMD (Table II).

Multivariate analysis by logistic regression was conducted to analyse the candidate risk factors for high IMD and oxidised triglycerides (OR = $0.0022, \mathrm{Cl}$ : 0.0001-0.04) and oxLDL (OR = 1.65, Cl: $1.30-2.10)$ were the retained $(p=0.0001)$. 
Table II. Correlation between the values of oxidative stress markers and IMD

\begin{tabular}{|lcccccc|}
\hline IMD & NO $[\mu \mathrm{mol} / \mathrm{l}]$ & AOPP $[\mu \mathrm{mol} / \mathrm{I}]$ & oxLDL $[\mu \mathrm{mol} / \mathrm{l}]$ & $\mathrm{MDA}[\mu \mathrm{mol} / \mathrm{l}]$ & $\mathrm{MPO}[\mathrm{U} / \mathrm{ml}]$ & Glutathione [U/ml] \\
\hline$<0.75$ & $60.78 \pm 1.16$ & $55.6 \pm 16.35$ & $6.44 \pm 0.63$ & $4.8 \pm 0.12$ & $52.69 \pm 2$ & $59.2 \pm 1.3$ \\
\hline $0.75-1$ & $64.42 \pm 2.03$ & $71.83 \pm 2.03$ & $26.41 \pm 1.65$ & $7.07 \pm 0.23$ & $70.03 \pm 4.32$ & $40.7 \pm 2.2$ \\
\hline$>1$ & $68.6 \pm 2.78$ & $81.38 \pm 2.78$ & $35.89 \pm 2.63$ & $7.9 \pm 0.17$ & $83.65 \pm 6.26$ & $33.5 \pm 1.8$ \\
\hline$P$-value & 0.002 & 0.0001 & 0.0001 & 0.0001 & 0.0001 & 0.0001 \\
\hline
\end{tabular}
density lipoprotein, MDA - malondialdehydes, MPO-myeloperoxidases.

\section{Discussion}

Candidate makers for oxidative stress were measured in CKD patients at different stages and compared to a control group. The levels of NO secreted by iNOS increased concomitantly with CKD stage progression, reaching the highest levels in haemodialysis patients (stage 5D). In the latter group, NO levels (mean \pm SD) were $72.45 \pm 2.17$ $\mu \mathrm{mol} / \mathrm{l}$, significantly higher than the control group $(52.19 \pm 2.1 \mu \mathrm{mol} / \mathrm{l})(p<0.05)$. Meenkshi and Agarwal [47], working on similar sample size, found that NO levels in haemodialysis patients were $98.77 \pm 35.40 \mu \mathrm{mol} / \mathrm{l}$ against $22.03 \pm 7.33 \mu \mathrm{mol} / \mathrm{l}$ in their control group.

We found that the levels of NO induced by iNOS were significantly higher in haemodialysis patients. This could be due to the dialysis procedure, which triggers an inflammatory reaction and cytokine production leading to iNOS upregulation [48]. At high concentrations, NO is a cytotoxic molecule responsible for dialysis complications and causes nutriant stress acting as a highly reactive free radical [49]. Comparing NO levels and $I M D$, we found that CKD patients with IMD $>1 \mathrm{~mm}$ had higher NO levels in their blood compared to those with IMD $<0.75 \mathrm{~mm}(68.6 \pm 2.78 \mu \mathrm{mol} / \mathrm{l}$ vs. $60.78 \pm 1.16 \mu \mathrm{mol} / \mathrm{l}, p<0.05)$. This result confirms those reported by Miyoshi et al., where they found that lack of NO synthesis by iNOS system in mice prevents the oxidation of oxLDL, thus preventing atherosclerosis development [50].

The levels of AOPP, a powerful oxidative stress marker, were concomitantly increasing with CKD stage progression (Figure 1). The lowest average levels of AOPP were reported in the control group $(26.65 \pm 1.05 \mu \mathrm{mol} / \mathrm{l})$, while the maximum levels were registered in haemodialysis patients $(82.75$ $\pm 2.19 \mu \mathrm{mol} / \mathrm{l})(p<0.0001)$. These findings confirm those reported by Véronique Witko-Sarsat et al. [36]. The authors reported a level of $29 \pm 4.9$ $\mu \mathrm{mol} / \mathrm{l}$ in the control group, compared to $42 \pm 2.6$ $\mu \mathrm{mol} / \mathrm{l}, 51 \pm 3.0 \mu \mathrm{mol} / \mathrm{l}$, and $72 \pm 4.4 \mu \mathrm{mol} / \mathrm{l}$ in CKD patients with moderate, severe symptoms, and haemodialysis patients, respectively $(p<0.001)$ [51]. AOPP are considered as uremic toxins [52] created during oxidative stress by the reaction of plasma proteins with chlorinated oxidants such as chloramines and acid hypochlorous [53], which are generated by phagocytic cells that have myeloperoxidase, the only enzyme able to generating chlorinated oxidants [54]. This activity is upregulated in CKD and haemodialysis patients [51].

As expected, CKD patients with a large IMD tended to have higher AOPP levels, compared to CKD patients with normal IMD (55.6 \pm 16.35 $\mu \mathrm{mol} / \mathrm{l}$ vs. $83.38 \pm 2.78 \mu \mathrm{mol} / \mathrm{l})(p=0.0001)$. These results are consistent with the findings of Yang et al. [55], who found that AOPP levels were correlated to IMD $(r=0.332, p<0.01)$ and patients with atherosclerotic plaques had higher rates of AOPP than those without plaques (73.87 \pm 19.40 $\mu \mathrm{mol} / \mathrm{l}$ vs. $58.41 \pm 16.09 \mu \mathrm{mol} / \mathrm{l})$.

Atherosclerosis is considered as an inflammatory disease with chronic fibroproliferation of the vascular wall [56]. In the present study, CRP levels was significantly higher in CKD patients compared to the control group. The fixation of monocytes and $T$ lymphocytes on the injured endothelium followed by their migration into the intima is one of the most crucial steps in the development of atherosclerotic lesions [57]. When monocytes and endothelial cells are activated, they express several active molecules such as adhesion molecules, cytokines, coagulation and fibrinolytic factors, metalloproteinases, and vasoactive substances [58]. All of these molecules could contribute to atherogenesis and thrombosis. A significant correlation between AOPP and monocyte activation markers was reported [59]. Thus, AOPP may represent a new class of proinflammatory and proatherogenic mediators [51].

The levels of oxLDL increased with the deterioration of renal function (Figure 1). The lowest average level of oxLDL was reported in the control group $(1.72 \pm 0.82 \mu \mathrm{mol} / \mathrm{l})$ while the highest level was registered in haemodialysis patients (35.78 $\pm 0.98 \mu \mathrm{mol} / \mathrm{l})(p<0.05)$. These finding are concomitant with those reported by Bergesioa [60], where oxLDL level was $24.25 \pm 12.3 \mu \mathrm{mol} / \mathrm{l}$ in the control group compared to $29.75 \pm 7.89 \mu \mathrm{mol} / \mathrm{l}$, $31.39 \pm 3.6 \mu \mathrm{mol} / \mathrm{l}, 48.25 \pm 5.46 \mu \mathrm{mol} / \mathrm{l}$, and 32.45 $\pm 5.63 \mu \mathrm{mol} / \mathrm{l}$ in CKD patients with moderate, severe symptoms, pre-haemodialysis, and haemodialysis stages, respectively. ROS are considered 
important mediators of renal failure. In fact, they are released by activated neutrophils and macrophages, which will oxidise apolipoproteins and generate oxLDL $[61,62]$. Comparing the oxLDL levels and IMD, we found a positive correlation between the two variables where patients with high IMD had higher IMD compared to patients with normal IMD $(6.44 \pm 0.63 \mu \mathrm{mol} / \mathrm{l}$ vs. $35.89 \pm 2.63$ $\mu \mathrm{mol} / \mathrm{l}, p=0.0001)$. Our findings support those reported by Klahr et al. [34] in which the average level of oxLDL in high IMD patients and those with atherosclerosis plaques was $48.3 \pm 2.3 \mu \mathrm{mol} / \mathrm{l}$ vs. $29.9 \pm 4.56 \mu \mathrm{mol} / \mathrm{l}$, respectively $(p<0.05)$ [63].

oxLDL plays an important role in the formation of atherosclerotic plaques because it is implicated in the penetration and oxidation of LDL passively in the vascular wall, followed by the adhesion of circulating monocytes. The latter is induced by the vascular cell adhesion molecule 1 (VCAM-1) and inter cellular adhesion molecule (ICAM-1) secreted in the case of endothelial cells dysfunction [64]. Monocyte chemoattractant protein-1 (MCP-1) and ICAM-1 are implicated in the migration and transform monocytes into macrophages. The latter capture oxLDL and transform into foam cells and produce proinflammatory mediators, mainly tumour necrosis factor $\alpha$ (TNF- $\alpha$ ) and interleukin 1 (IL-1) and anti-inflammatory cytokine (IL-10), inducing a state of chronic inflammation as well as proliferation of VSMCs [65]. These stages represent the beginning of atherosclerosis plaque formation.

MDA levels increased with the progression of CKD stage, where the lowest average levels of MDA were reported in the control group, while haemodialysis patients had the highest levels (3.26 \pm 0.03 $\mu \mathrm{mol} / \mathrm{l}$ vs. $8.27 \pm 0.11 \mu \mathrm{mol} / \mathrm{l}, p<0.05)$. Our findings are similar to those reported by Witko-Sarsat et al. [66], where the lowest MDA levels were reported in control $(2.5 \pm 0.17 \mu \mathrm{mol} / \mathrm{l})$ and CKD patients with moderate symptoms $(3.0 \pm 0.08 \mu \mathrm{mol} / \mathrm{l})$ $(p<0.05)$, while the highest levels were registered in severe $(3.0 \pm 0.05 \mu \mathrm{mol} / \mathrm{l})$ and final-stage CKD $(3.2 \pm 0.09 \mu \mathrm{mol} / \mathrm{l})$. It is known that uraemic toxins increase lipid peroxidation, and this phenomenon is more important in haemodialysis patients [67]. In a study conducted by Capeillere-Blandin et al. [68], the highest levels of MPO were reported in haemodialysis patients, and the lowest levels were seen in the control group $(88.65 \pm 4.09 \mathrm{U} / \mathrm{l}$ vs. $38.45 \pm 1.93 \mathrm{U} / \mathrm{l}, p<0.05$ ). This difference was also observed in patients at different CKD stages and in haemodialysis patients.

Patients with high IMD $(r=0.536, p=0.015)$ and LVH $(r=0.816, p<0.001)$ had higher MDA levels. Therefore, the increase in oxidative stress and inflammatory markers contributes to the occurrence of early cardiovascular damage in young CKD patients [69]. MDA participate in cardiovascular complications by binding to modified ox-
LDL to facilitate its absorption by macrophages, transforming them into foam cells and contributing to atherosclerosis plaque formation [70, 71]. Furthermore, MDA could modify endothelial cells and VSMCs function inducing lesions of atherosclerosis development [72].

MPO levels were the highest in haemodialysis patients and the lowest in the control group $(88.65 \pm 4.09 \mathrm{U} / \mathrm{l}$ vs. $38.45 \pm 1.93 \mathrm{U} / \mathrm{l})(p<0.05)$. This difference was also observed in patients with different CKD stages and haemodialysis patients. Capeillere-Blandin et al. [68] reported a significant difference in MPO levels between haemodialysis patients and the control group (39 $\pm 4 \mathrm{ng} / \mathrm{ml}$ vs. $13.3 \pm 0.5 \mathrm{ng} / \mathrm{ml}, p<0.001)$ and between pre-haemodialysis and haemodialysis patients (15.3 \pm 1.1 $\mathrm{ng} / \mathrm{ml}$ vs. $39 \pm 4 \mathrm{ng} / \mathrm{ml})(p<0.001)$. MOP is an oxidoreductase, present in some phagocytic cells such as neutrophils and macrophages, and it is implicated in the formation of hypochlorous acid $(\mathrm{HOCl})$, a reactive oxygen species (ROS), which is extremely pro-oxidant and which destroys the pathogen and represents a source of ROS formation in haemodialysis patients [73].

IMD was positively associated with MOP levels where the highest levels were registered in patients with high IMD. This result confirms the literature findings [74]. It is well documented that MPO initiates and contributes to the development of atherosclerosis, endothelial dysfunction, cardiovascular disease, and other complications in patients with coronary artery disease [75]. Furthermore, $\mathrm{HOCl}$ affects endothelial cell function by decreasing the adhesion of proteins in renal cell matrix and accelerating atherosclerosis [76].

Unlike the above markers, the glutathione levels were negatively correlated with the CKD stage, and the lowest average levels were reported in haemodialysis patients, while the control had the highest levels $(29.9 \pm 0.8 \mathrm{lU} / \mathrm{ml}$ vs. $89.4 \pm 2.6 \mathrm{IU} /$ $\mathrm{ml}, p<0.05)$. These findings are concomitant with those reported by Picot et al. [77]. Another study conducted by Tbhariti et al. [78] on 167 CKD patients from different stages showed glutathione levels to be $7.71 \pm 0.01,6.62 \pm 0.50,5.23 \pm 0.23$, $5.01 \pm 0.82,3.99 \pm 1.39$, and $4.94 \pm 1.12 \mathrm{U} / \mathrm{ml}$ ) in CKD stage 1, 2, 3, 4, haemodialysis, and peritoneal dialysis patients, respectively $(p<0.001)$. These results confirm our findings that glutathione levels decrease with the progression of CKD [79]. Glutathione concentrations decrease considerably in the blood stream of haemodialysis patients due to several factors, mainly the bio-incompatibility of the dialyser and endotoxins [80].

Patients with high IMD had low glutathione levels, compared to those with normal IMD (59.2 $\pm 1.3 \mathrm{lU} / \mathrm{ml}$ vs. $33.5 \pm 1.8 \mathrm{IU} / \mathrm{ml}, p=0.0001)$. These results confirm those obtained by Dursun et al. [81], who stated that glutathione level is 
a representative marker for the antioxidant activity, while high IMD was a sign of atherosclerosis.

In conclusion, patients with CKD are at high risk of developing cardiovascular disease. We found that the acceleration of the atherosclerosis process is very common in patients with severe CKD and haemodialysis patients, and oxidative stress markers increase significantly with the progression of CKD, with the highest values, except for glutathione, seen in haemodialysis patients. This latter group is affected by many external factors such as the contact of blood with biocompatible membranes, which increase the effect of oxidative stress. Furthermore, oxLDL was found to be highly implicated in the development and progression of atherosclerosis, and its measurement could help in the early diagnosis of different cardiovascular diseases. For the management of atherosclerosis and other cardiovascular diseases in CKD patients we think that reducing the level of oxLDL would be an open treatment strategy to be investigated in further studies.

The sample size was a major limitation of the study, and we are working to overcome this and recruit more patients in order to have a representative sample size for the general population. Furthermore, since uric acid is usually increased in CKD patients and is associated with more severe atherosclerosis, we would like to measure it in further studies. Besides, the duration of the study was not sufficient, and we believe that a longer study duration is needed to draw solid conclusions on the oxidative stress markers and the evolution of atherosclerosis following vitamin $\mathrm{E}$ intake in CKD patients.

\section{Conflict of interest}

The authors declare no conflict of interest.

\section{References}

1. Stenvinkel P. Chronic kidney disease: a public health priority and harbinger of premature cardiovascular disease. J Intern Med 2010; 268: 456-67.

2. Mallappallil M, Friedman EA, Delano BG, Farlane S, Salifu MO. Chronic kidney disease in the elderly: evaluation and management. Clin Pract 2014; 11: 525-35.

3. Boer IH, Rue TC, Hall YN, Heagerty PJ, Weiss NS, Himmelfarb J. Temporal trends in the prevalence of diabetic kidney disease in the United States. JAMA 2011; 305 2532-9.

4. Saran R, Robinson B, Abbott KC, et al. US Renal Data System 2018 Annual Data Report: Epidemiology of Kidney Disease in the United States. Am J Kidney Dis 2019; 73: 291-332.

5. Grams ME, Chow EK, Segev DL, Coresh J. Lifetime incidence of CKD stages 3-5 in the United States. Am J Kidney Dis 2013; 62: 245-52.

6. Sarnak MJ. Cardiovascular complications in chronic kidney disease. Am J Kidney Dis 2003; 41 (5 Suppl): 11-7.

7. Parikh NI, Hwang SJ, Larson MG, Meigs JB, Levy D, Fox CS. Cardiovascular disease risk factors in chronic kidney disease: overall burden and rates of treatment and control. Arch Intern Med 2006; 166: 1884-91.

8. Cohen EP, Krzesinski JM. The physiopathology of dialysis-associated hypertension. Nephrol Ther 2007; 3: 150-5.

9. Saran R, Robinson B, Abbott KC, et al. US Renal Data System 2016 Annual Data Report: Epidemiology of Kidney Disease in the United States. Am J Kidney Dis 2017; 69: 1-688.

10. Paraskevas KI, Kotsikoris I, Koupidis SA, Tzovaras AA, Mikhailidis DP. Cardiovascular events in chronic dialysis patients: emphasizing the importance of vascular disease prevention. Int Urol Nephrol 2010; 42: 999-1006.

11. Bronas UG. Exercise training and reduction of cardiovascular disease risk factors in patients with chronic kidney disease. Adv Chronic Kidney Dis 2009; 16: 44-58.

12. Sies H. Oxidative Stress. Academic Press, London 1985.

13. Garg AX, Clark WF, Haynes RB, House AA. Moderate renal insufficiency and the risk of cardiovascular mortality: results from the NHANES I. Kidney Int 2002; 61: 1486-94.

14. Madore F. Facteurs de risque vasculaires et insuffisance rénale. Médecine Sciences 2004; 20: 1100-3.

15. Berdeaux O, Scruel O, Durand T. Isoprostanes, biomarkers of lipid peroxidation in humans. Part 2: quantification methods. Pathol Biol 2005; 53: 356-63.

16. Grzebyk E, Piwowar A. Inhibitory actions of selected natural substances on formation of advanced glycation end products and advanced oxidation protein products. Complement Altern Med 2016; 16: 38-41.

17. Butkowski EG, Al-Aubaidy HA, Jelinek HF. Interaction of homocysteine, glutathione and 8-hydroxy-2'-deoxyguanosine in metabolic syndrome progression. Clin Biochem 2016; 15: 22-36.

18. Haleng J, Pincemail J, Defraigne JO, Charlier C, Chapelle JP. Le stress oxydant. Rev Med Liege 2007; 62: 628-38.

19. Čolak E, Ignjatović S, Radosavljević A, Žorić L. The association of enzymatic and non-enzymatic antioxidant defense parameters with inflammatory markers in patients with exudative form of age-related macular degeneration. J Clin Biochem Nutr 2017; 60: 100-7.

20. Weiner DE, Tabatabai S, Tighiouart H, et al. Cardiovascular outcomes and all-cause mortality: exploring the interaction between CKD and cardiovascular disease. Am J Kidney Dis 2006; 48: 392-401.

21. Migdal C, Serres M. Especes reactives de l'oxygene et stress oxydant. Med Sci 2011; 27: 405-12.

22. Maziere C, Gomila C, Maziere JC. Oxidized low-density lipoprotein increases osteopontin expression by generation of oxidative stress. Free Radic Biol Med 2010; 48: 1382-7.

23. Beaudeux JL, Peynet J, Bonnefont-Rousselot D, et al. Cellular sources of reactive oxygen and nitrogen species. Roles in signal transcription pathways. Ann Pharm Fr 2006; 64: 373-81.

24. Bogna G, Dorota F, Magdalena B, et al. Advanced oxidation protein products and carbonylated proteins as biomarkers of oxidative stress in selected atherosclerosis-mediated diseases. Biomed Res Int 2017; 20: 487-97.

25. Gao L, Mann GE. Vascular NAD(P)H oxidase activation in diabetes: a double-edged sword in redox signalling. Cardiovasc Res 2009; 82: 9-20.

26. Beaudeux JL, Dellatre J, Therond P, Bonnefont-Rousselot D, Legrand G, Peynet J. Le stress oxydant, composante physiopathologique de l'athérosclérose. Immuno-analyse Biologie Spécialisée 2006; 21: 144-50. 
27. hyun Choi B, Kang KS, Kwak MK. Effect of redox modulating NRF2 activators on chronic kidney disease. Molecules 2014; 19: 12727-59.

28. Gerdes N, Sukhova GK, Libby P, Reynolds RS, Young J, Schonbeck U. Expressionof interleukin (IL)-18 and functional IL-18 receptor on human vascular endothelialcells, smooth muscle cells, and macrophages: implications for atherogenesis. J Exp Med 2002; 195: 245-57.

29. Shen G, Jing L. Association between circulating oxidized low-density lipoprotein and atherosclerotic cardiovascular disease. Chron Dis Transl Med 2017; 3: 89-94.

30. Meier P, Spertini F, Blanc E, Burnier M. Oxidized low density lipoproteins activate $\mathrm{CD}^{+} \mathrm{T}$ cell apoptosis in patients with end-stage renal disease through Fas engagement. Am Soc Nephrol 2007; 18: 331-42.

31. Kita T, Kume N, Minami M, et al. Role of oxidized LDL in atherosclerosis. Ann N Y Acad Sci 2001; 947: 199-205.

32. Bresgen N, Eckl PM. Oxidative stress and the homeodynamics of iron metabolism. Biomolecules 2015; 5 : 808-47.

33. Kellum JA, Lameire N. Recommendations Kidney Disease Improving Global (KDGO). Kidney Int 2012; 2: 19-36.

34. Klahr S, Levey AS, Beck JG, et al. The effects of dietary protein restriction and blood pressure control on the progression of chronic renal disease. N Engl J Med 1994; 330: 877-84.

35. Witko V, Nguyen AT, Descamps-Latscha B. Microtiter plate assay for phagocyte-derived taurine-chloramines. J Clin Lab Anal 1992; 6: 47-53.

36. Witko-Sarsat V, Friedlander M, Capeille're-Blandin C, et al. Advanced oxidation protein products as a novel marker of oxidative stress in uremia. Kidney Int 2001; 49: 13-4.

37. Grand F, Guitton J, Goudable J. Optimisation des paramètres du dosage des nitrites et nitrates sériques par la technique de Griess. Journal etude 2001; 59: 243-7.

38. Benjamin P, Muhammad A, Forghani R, et al. Measuring myeloperoxidase activity in biological samples. PLoS One 2013; 8: 47-52.

39. Richard MJ, Belleville F, Chalas J, et al. Les glutathion peroxydases: intérêt de leur dosage en biologie clinique. Ann Biol Clin 1997; 55: 52-7.

40. Human Oxidized low-density lipoprotein (OxLDL) ELISA Kit. Product Manual. Catalog No. abx253899.

41. Michel D, Rousselot B, Mas EJ. Biomarqueurs de la peroxydation lipidique: aspects analytiques. Ann Biol Clin 2008; 66: 605-20.

42. Roberto M, Lang MD, Bierig M, et al. American Society of Echocardiography's Guidelines Standards Committee and the Chamber Quantification Writing Group, Developed in Conjunction with the European Association of Echocardiography, a Branch of the European Society of Cardiology. Recommendations for Chamber Quantification. J Am Soc Echocardiogr 2005; 18: 1440-63.

43. Klimczak C. Echocardiographie clinique. $7^{\text {th }}$ ed. Elsevier Masson 2016; 99-101.

44. Sesso HD, Stampfer MJ, Rosner B, et al. Systolic and diastolic blood pressure, pulse pressure and mean arterial pressure as predictors of cardiovascular risk in men. Hypertension 2000; 36: 801-7.

45. Latreche S. L'échodoppler cardiaque dans l'hypertension artérielle. Médecine du Maghreb 2001; 92; 25-8.

46. Fanantenana HN, Lova Hasina N, Rajaonarison N, et al. Thickness of carotid intima-media and cardiovascular risk factors. PAN African Med J 2015; 236: 23-9.
47. Meenakshi SR, Agarwa I. Nitric oxide levels in patients with chronic renal disease. J Clin Diagn Res 2013; 7: 1288-90.

48. Stratta P, Canvese C, Dogliani M, et al. The role of free radicals in the progression of renal disease. Am J Kid Dis 1991; 17: 33-7.

49. Aiello S, Noris M, Todesehini M, et al. Renal and systemic NO synthesis in rats with renal mass reduction. Kidney Int 1997; 52: 171-81.

50. Miyoshi T, Li Y, Shih DM, Wang X, Laubach VE, Matsumoto AH. Deficiency of inducible NO synthase reduces advanced but not early atherosclerosis in apolipoprotein E-deficient mice. Life Sci 2006; 79: 525-31.

51. Witko-Sarsat V, Drüeke T, Descamps-Latscha B, Canteloup S. Advanced oxidation protein products as novel mediators of inflammation and monocyte activation in chronic renal failure. J Immunol 1998; 161: 2524-32.

52. Tucker PS, Dalbo VJ, Han T, Kingsley MI. Clinical and research markers of oxidative stress in chronic kidney disease. Biomarkers 2013; 18: 103-15.

53. Zhou Q, Wu S, Jiang J, et al. Accumulation of circulating advanced oxidation protein products is an independent risk factor for ischaemic heart disease in maintenance haemodialysis patients. Nephrology 2012; 17: 642-9.

54. Li HY, Hou FF, Zhang X, et al. Advanced oxidation protein products accelerate renal fibrosis in a remnant kidney model. J Am Soc Nephrol 2007; 18: 528-38.

55. Yang XB, Hou FF, Wu Q, et al. Increased levels of advanced oxidation protein products are associated with atherosclerosis in chronic kidney disease. NCBI 2005; 44: 342-6.

56. Tuttolomondo A, Di Raimondo D, Pecoraro R, et al. Atherosclerosis as an inflammatory disease. Curr Pharm Des 2012; 18: 4266-88.

57. Schmitz G, Herr AS, Rothe G. T-lymphocytes and monocytes in atherogenesis. Herz 1998; 23: 168-77.

58. Ikeda U, Takahashi M, Shimada K. Monocyte-endothelial cell interaction in atherogenesis and thrombosis. Clin Cardiol 1998; 21: 11-4.

59. Descamps-Latscha B, Witko-Sarsat V. Advanced oxidation protein products as risk factors for atherosclerotic cardiovascular events in nondiabetic predialysis patients. Am J Kidney Dis 2005; 45: 39-47.

60. Bergesioa F, Monzanib R, Ciutic C, et al. Autoantibodies against oxidized LDL in chronic renal failure: role of renal function, diet, and lipids. Nephron 2001; 87: 127-33.

61 . Klahr S. Oxygen radicals and renal diseases. Miner Electrolyte Metab 1997; 23: 140-3.

62. Verma S, Buchanan MR, Anderson TJ. Endothelial function testing as a biomarker of vascular disease. Circulation 2003; 108: 2054-9.

63. Stenvinke IP, Heimbürger O, Paultre F, Diczfalusy U, Wang T, Berglund L. Strong association between malnutrition, inflammation, and atherosclerosis in chronic renal failure. Kidney Int 1999; 55: 1899-911.

64. Strong JP, Bhattacharyya AK, Eggen DA, et al. Long-term induction and regression of diet-induced atherosclerotic lesions in rhesus monkeys. II. Morphometric evaluation of lesions by light microscopy in coronary and carotid arteries. Arterioscler Thromb 1994; 14: 2007-16.

65. Dania M, Pibarot P, Despres JP, Claude C. Association between plasma LDL particle size, valvular accumulation of oxidized LDL, and inflammation in patients with aortic stenosis. Arterioscler Thromb Vasc Biol 2017; 19: 56-7.

66. Witko-Sarsat V, Gausson V, Descamps-Latscha B. Are advanced oxidation protein products potential uremic toxins? Kidney Int Suppl 2003; 84: 11-4. 
67. De Vecchi AF, Caroline S. Free and total plasma malondialdehyde in chronic renal insufficiency and in dialysis patients. Nephrol Dialysis Transpl 2009; 24: 2524-9.

68. Capeillère-Blandin C, Gausson V, Nguyen A, et al. Respective role of uraemic toxins and myeloperoxidase in the uraemic state. Nephrol Dialysis Transpl 2006; 21: 1555-63.

69. Ece A, Gürkan F, Kervancıoğlu M, Kocamaz H, llyas Y. Oxidative stress, inflammation and early cardiovascular damage in children with chronic renal failure. Pediatr Nephrol 2006; 21: 545-52.

70. Holvoet P, Vanhaecke J, Janssens S, et al. Oxidized LDL and malondialdehyde-modified LDL in patients with acute coronary syndromes and stable coronary artery disease. Circulation 1998; 98: 1487-90.

71. Amedeo F, DeVecchi F, Bamonti C, et al. Free and total plasma malondialdehyde in chronic renal insufficiency and in dialysis patients. Nephrol Dialysis Transplant 2009; 24: 2524-9.

72. Sasikala M, Sadasivudu B, Subramanyam C. A putative role for calcineurin in lymphopenia associated with chronic renal failure. Clin Biochem 2000; 33: 691-4.

73. Kisic B, Dijana M, Dragojevic I. Role of myeloperoxidase in patients with chronic kidney disease. Oxid Med Cell Longev 2016; 14: 36-42.

74. Hirokazu H, Masashi U, Akizawa T. Assessment of myeloperoxidase and oxidative alpha1-antitrypsin in patients on hemodialysis assessment of myeloperoxidase and oxidative apha1-antitrypsin in patients on hemodialysis. Clin J Am Soc Nephrol 2009; 4: 142-51.

75. Libetta C, Sepe V, Esposito P, Galli F. Oxidative stress and inflammation: implications in uremia and hemodialysis. Clin Biochem 2011; 44: 1189-98.

76. Fu X, Kassim SY, Parks XC, Heinecke J. Hypochlorous acid generated by myeloperoxidase modifies adjacent tryptophan and glycine residues in the catalytic domain of matrix metalloproteinase-7 (matrilysin). An oxidative mechanism for restraining proteolytic activity during inflammation. J Biol Chem 2003; 278: 28403-9.

77. Picot C, Witko Sarat V, Merad Boudia M, et al. Gluthation antioxidant system as a marker of oxidative stress in chronic renal failure. Free Rad Biol Med 1996; 21: 845-53.

78. Tbahriti HF, Kaddous A, Bouchenak M, Mekki K. Effect of different stages of chronic kidney disease and renal replacement therapies on oxidant-antioxidant balance in uremic patients. Biochem Res Int 2013; 25: 475-6.

79. Tepel $M$, van $\operatorname{der}$ Giet $M$, Statz $M$, et al. The antioxidant acetylcysteine reduces cardiovascular events in patients with end-stage renal failure: a randomized, controlled trial. Circulation 2003; 107: 992-5.

80. Nguyen-Khoa T, Massy ZA, De Bandt JP, et al. Oxidative stress and haemodialysis: role of inflammation and duration of dialysis treatment. Nephrol Dial Transplant 2001; 16: 335-40.

81. Dursun B, Dursun E, Suleymanlar G, Ozben Irfan B, Apaydin A, Ozben T. Carotid artery intima-media thickness correlates with oxidative stress in chronic haemodialysis patients with accelerated atherosclerosis. Nephrol Dialysis Transpl 2008; 23: 1697-703. 